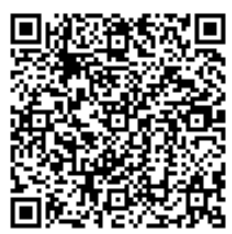

\title{
The Play Specialist in the Pediatric Healthcare: Evidence-Based Professionalism, Issues in Practice, and Training Across Different Countries
}

\author{
Perasso G. ${ }^{1,2}$ (iD \\ ${ }^{1}$ University of Milano-Bicocca, Italy \\ ${ }^{2}$ Il Porto dei Piccoli Onlus, Italy
}

Received: 25.03.2021; Accepted: 01.06.2021; Published: 30.06 .2021

\begin{tabular}{|c|c|}
\hline Keywords: & Play, hospital, children, play specialist, training \\
\hline Copyright: & $\begin{array}{l}\text { (C) } 2021 \text { Perasso G. Published by Archives of International Journal of Science } \\
\text { Annals }\end{array}$ \\
\hline DOI and UDC & DOI https://doi.org/10.26697/ijsa.2021.1.7 UDC 159.9:615.851.8 \\
\hline Conflict of interests: & The author declares that there is no conflict of interests \\
\hline Peer review: & Double-blind review \\
\hline Source of support: & This study did not receive any outside funding or support \\
\hline $\begin{array}{r}\text { Information about } \\
\text { the author: }\end{array}$ & $\begin{array}{l}\text { Perasso Giulia }- \\
\text { ricerche@ilportodeipiccoli.org; Doctor of Philosophy in Psychology, } \\
\text { Neuroscience, Data Science, Department of Psychology, University of Milano- } \\
\text { Bicocca, Milan, Italy; Research Consultant, Porto dei Piccoli Onlus, Genoa, Italy. }\end{array}$ \\
\hline
\end{tabular}

\section{Dear Editor,}

For developmental psychologists, playing is a crucial parameter to monitor children and adolescents' physical, emotional, cognitive, and executive development and wellbeing. In the psychotherapy setting, play is a promotor of positive therapeutic change because it allows the child to express beliefs, memories, wishes, feelings, and subconscious contents, from a safe and indirect point of view. Play is a fundamental human right during the whole life cycle, and it becomes even more important for those children and adolescents who are hospitalized or experiencing medical treatments at home (European Association for Children in Hospital, 1988). Entering a medical setting can elicit children's and adolescents' distress on many levels (e.g., anxiety, depression, hypochondria, acting out, externalizing, and internalizing problems) since their familiar routine is temporarily disrupted.

In the 1920s the nurses Florence Nightingale and Florence Erikson were the first to intuit the power of play for hospitalized children: the pediatric patients who could experience play sessions with a properly trained professional were more adherent towards medical treatments (Francischinelli et al., 2012). Play can make the hospital experience enjoyable, or at least less terrifying for the youngsters. Back then, many synonyms were used to describe this role like "play-lady", "puppet lady", "play checkers", "playing teacher", and "recreational therapist". Nowadays, there is a great terminological fragmentation in describing all the professionals trained to support children during hospitalization through age-specific and diagnosisspecific play programs. Different countries adopt different labels to describe this role, which can be defined by the keyword "Play Specialist" (Porto dei Piccoli, 2021). Play Specialist intervention differs from Play Therapy because Play Therapy is a projective technique practiced by psychotherapists in the light of a psychoanalytical framework. Play Specialist's intervention, instead, can be summarized into two coreactions (Burns-Nader \& Hernandez-Reif, 2014): 1) medical play: using medical equipment and language to help the child to get used and not fear the medical setting and procedures; 2) normative play: proposing play activities to the child that are similar to play activities he or she practices at home. This establishes a sense of continuity with the life before illness, and/or offers distractions and imaginary escapes from reality. Noticeably, the Play Specialist can also offer to children with chronic conditions (e.g., diabetes or disabilities) experiential activities outside of the children's comfortzone, to increase their health-related responsibility and self-efficacy.

The aim of the study. To foster scientific community consideration about the Play Specialist role, paying 
attention to the state of the art, the international field of practice, the evidence supporting the effectiveness of the Play Specialist intervention, the main challenges, and the everyday issue that these professionals have to face to gain proper integration in the national and international healthcare system.

This contribution presents two main elements: a literature review and a small-group survey. A review of the literature (on a total of $n=613$ papers from Pubmed, Scopus, PsycArticles) has been conducted to describe the Play Specialist professionalism and the difficulties in the practice. Moreover, the core elements of the training across different nations in terms of the prerequisites, the duration of the training, the institutions promoting or certifying the training, and the study subjects are discussed from an inclusive perspective. Thus, data from $\mathrm{n}=9$ international experts in the field are examined to describe the state of the art over the Play Specialist's training.

Literature offers a vast body of evidence supporting the Play Specialist's intervention effectiveness in fostering the hospitalized child's wellbeing.

Five key elements emerged:

1. The Play Specialist intervention improves the child's coping strategies, her/his positive emotions, and decreases anxiety and stress that may anticipate medical procedures (Gill, 2010; Ullan \& Belver, 2019).

2. Children require less sedation for pain management: with the Play Specialist intervention, the child is more capable of pain management at a behavioral, physical, cognitive, and complementary level (Bandstra et al., 2008).

3. The child is more adherent to the medical treatment: since play intervention decreases negative emotions (e.g., anxiety, stress, externalizing behaviors) the child is more collaborative towards medical staff (Gill, 2010). Once achieved through medical play a major knowledge over her/his health and the healing process, the child experiences less power imbalance from the adults taking care of her/him (e.g., family members, medical staff) (Bricher, 2000).

4. Play can be crucial in palliative care: through targeted play activities the Play Specialist can help the child to face and elaborate emotions connected to end-of-life concepts (Lindqvist, 1974).

5. Time and economic savings for the hospitals: as supported by Metzger et al. (2013), the Play Specialist enhances patients' compliance, requiring less anesthesia for invasive medical procedures. This aspect is important to spare sedation costs to the hospital, and also to spare children from anesthesia and its potential collateral effects.

Literature depicts the main challenges that the Play Specialists have to face all over the world.

Five main domains emerge:

1) Lack of standardized methods and measures to support the practice (Goh et al., 2019) has hindered for a very long-time the possibility to create a common ground;

2) Practice fragmentation across different countries arise problems in the practice as the core activities are often overlapping with other professionals' interventions like educational video gaming, pet therapy, art therapy;

3) Lack of recognition at a national and international level hinders the integration of the Play Specialist with the hospital staff (Metzger et al., 2013). Frequently, doctors and nurses may exchange Play Specialists for volunteers or may improvise play activities for their patients without having the proper training;

4) Lack of funds from national institutions represent another crucial challenge for promoting the Play Specialist as no-profit private institutions often support this professionalism (Simonelli et al., 2014);

5) Difficulties in accessing the hospitals for Play Specialist during Covid-19 waves emerged. To respond to the global crises without letting down families and children, pioneering telematic adaptations of the Play Specialist intervention have been developed (Perasso et al., 2020).

Experts offer a detailed picture of the Play Specialist formation at an international level. Data collected from the nine participants to Porto dei Piccoli's international Round Table (January 2021), reveal salient elements in the Play Specialist formation.

Across different countries, heterogeneities and commonalities emerge:

- the prerequisite of the training (e.g., a bachelor's degree in psychology or pedagogy) is required all over the world;

- the duration of the formation varies from courses of 200 hours to courses of 760 hours;

- considering the subjects of the Play Specialists' study, the countries' referents agree about offering formation on the child developmental milestones on a pediatric, psychological, pedagogical level, play-techniques, family psychology, attachment psychology;

- as regards achieving a certification at the end of the training, a few countries still struggle to obtain institutional recognition for Play Specialists and proper certification procedures. In fact, institutional certification is fundamental in providing evidence-based interventions and obtaining acknowledgment in the hospital context.

The Play Specialist's professionalism is essential to advocate children's right to play in the hospital context and to promote her/his wellbeing by fostering coping, treatment adherence, and counteracting negative emotions. Still, cross-countries differences at an educational and institutional recognition level hinder the possibility to integrate the Play Specialists in national and international healthcare systems. For the future, the exchange of best practice and research evidence among no-profit organizations, and public and private healthcare stakeholders is vividly recommended to build a common ground and finally overcome fragmentation.

\footnotetext{
References

Bandstra, N. F., $\quad$ Skinner, L., $\quad$ Leblanc, C., Chambers, C. T., Hollon, E. C., Brennan, D., \& Beaver, C. (2008). The role of child life in pediatric pain management: A survey of child life specialists. The Journal of Pain, 9(4), 320-329. https://doi.org/10.1016/j.jpain.2007.11.004
} 
Bricher, G. (2000). Children in the hospital: Issues of power and vulnerability. Pediatric Nursing, 26(3), 277-282. https://pubmed.ncbi.nlm.nih.gov/12026391/

Burns-Nader, S., \& Hernandez-Reif, M. (2016). Facilitating play for hospitalized children through child life services. Children's Health Care, 45(1), $1-21$. https://doi.org/10.1080/02739615.2014.948161

European Association for Children in Hospital. (1998). The EACH Charter. https://www.each-for-sickchildren.org/each-charter

Francischinelli, A. G. B., Almeida, F. D. A., $\quad$ \& Fernandes, D. M. S. O. (2012). Routine use of therapeutic play in the care of hospitalized children: Nurses' perceptions. Acta Paulista de Enfermagem, 25(1), 18-23. https://doi.org/10.1590/S0103-21002012000100004

Gill, C. (2010). Helping children cope with renal disease: the role of play specialist. Journal of Renal Nursing, $2(5)$, 244-247. https://doi.org/10.12968/jorn.2010.2.5.78490

Goh, G., Edmonds, L., \& Christos, J. (2019). Development and evaluation of play specialist documentation in a New Zealand hospital. Nursing Children and Young People, 31(2), 3236. https://doi.org/10.7748/ncyp.2019.e1144

Lindqvist, I. (1974). Play as therapy. Pediatrician, 3, 295-300.

Metzger, T., Mignogna, K., \& Reilly, L. (2013). Child life specialists: Key members of the team in pediatric radiology. Journal of Radiology Nursing, 32(4), 153-159. https://doi.org/10.1016/j.jradnu.2013.08.001

Perasso, G., Maggiore, A., Allegri, C., \& Camurati, G. (2020). Telematic intervention based on the Play Specialist approach in the COVID-19 era: Benefits for parents of children with clinical conditions. International Journal of Preventive Health and Medicine, 1(1), 1-7. https://doi.org/10.35940/ijpmh.A2005.111120

Porto dei Piccoli. (2021, 29 January). 1st International Round Table on Playing in the Hospital. https://www.ilportodeipiccoli.org/it-it/roundtable-e-play-specialist/

Simonelli, I., Raúl, M., Bennett, S., Clarke, A., Fernandes, G. A. I., Fløtten, K., Maggi, S., Robinson, J. E., $\quad$ Simonelli, F., Vaghri, Z., Webb, E., \& Goldhagen, J. (2014). A rights and equity-based "Platform and Action Cycle" to advance child health and well being by fulfilling the rights of children. Canadian Journal of Children's Rights, 1(1), 199-218. https://doi.org/10.22215/CJCR.V1I1.11

Ullan, A. M., \& Belver, M. H. (2019). Integrative pediatrics and child care play as a source of psychological well-being for hospitalized children: Study Review. Integrative Pediatrics and Child Care, 2(1), 92-98. https://doi.org/10.18314/ipcc.v2i1.1613

\section{Cite this article as:}

Perasso, G. (2021). The Play Specialist in the pediatric healthcare: Evidence-based professionalism, issues in practice, and training across different countries. International Journal of Science Annals, 4(1), 45-47. https://doi.org/10.26697/ijsa.2021.1.7

The electronic version of this article is complete. It can be found online in the IJSA Archive https://ijsa.culturehealth.org/en/arhiv and in the KRPOCH Publishing Repository https://ekrpoch.culturehealth.org/handle/lib/71 the original work is properly cited (http://creativecommons.org/licenses/by/4.0/deed.en). 